tegrity, and four-storied buildings with intercommunications should have been avoided. On the cellar floor is a very perfect tramway arrangement, running round the whole of the buildings, and connected at intervals with staircases and lifts. I fear that this may become a source of danger in the future. The placing of additional patients in the attics in times of epidemic or other pressure, does not appear to me to be a judicious proceeding; and the intercalation of supernumerary beds (brancards, of which I saw two), in the ordinary sick wards, is an unmixed evil. The great ventilating chimney may also act prejudicially on the neighbouring dwellings, as similar structures are supposed to have done elsewhere in Paris.

The hospital has been too short a time in existence, to admit of any opinion being formed as to its superiority to the other institutions of the same class and character in the same city. I ought to have mentioned that it is supplied with a well-arranged series of railways and lifts, and has a complete system of electric bells throughout. Suitable mechanical arrangements for weighing and distributing fuel, and lightning conductors, have also been provided.

( $T$ o be continued.)

\section{A NEW LINE OF RESEARCH BEARING ON THE PHYSIOLOGY OF SUGAR IN THE ANIMAL SYSTEM.'}

Bx F. W. PAVY, M.D., F.R.S.

TWENTY-THREE years ago I presented a communication to the Royal Society, entitled "On the alleged Sugar" forming Function of the Liver."

Four years previously-viz., in 1854, whilst conducting experiments directed towards determining the manner in which the sugar presumed, under the glycogenic doctrine, to escape from the liver was destroyed (as it was then believed to be) in the lungs, I discovered that what had been taken as representing the natural condition of the liver, and of the blood escaping from it in relation to sugar, was founded upon a fallacious inference. By those who have only been acquainted with what, in recent times, has been recognised as constituting the state existing, the original position in which the matter stood will hardly be fully compcehended. The strongly saccharine state in which the liver and the blood of the hepatic veins are found shortly after death was looked upon, without any question being raised about it, as representing the state existing during life. Without the alightest prior conception that such was likely to be the case, I found, first, that the blood between the liver and the lungs was not during life in the condition that had been supposed, and, next, that what I discovered for the blood applied also to the liver. The evidence which presented itself led me, as is known, to dispute the validity of the glycogenic theory, and the additional information which $I$ have since from time to time obtained has materially strengthened the position I took. To my own mind the conditions that we have to deal with, looked at in their entirety, are totally irreconcilable with the glycogenic theory; but I know that the difficulty which has existed in accounting for the disposal of the glycogenic matter of Bernard encountered in the liver has stood in the way of a general adoption of my views. This subject, however, I am now prepared to approach and consider.

When the glycogenic matter was discovered, it was described as undergoing transformation into sugar immediately it was brought into contact with blood. Bernard said of it: "Cette dernière [matière glycogène $d u$ foie] est tellement alterable qu'elle ne peut pas exister dans le sang sans être immédiatement changée en sucre, de sorte qu'elle ne peut jamais sortir du foie que sous cet état." This impression has governed the position left open to us to take in relation to the disposal of the material, and rendered it necessary to look for some undiscovered mode of transformation of it

I A paper read at the Royal Society, June 8th, 1881. within the liver under the presumption that it does not reach the circulating system as sugar.

We have here a fundamental point to deal with; and, as in my original communication to the Society, I had to commence by clearing the ground of error, so now it happens that I have to proceed in a similar way in relation to the point in question. I have results to communicate which appear to me to place us in a new position, but before these are considered it is requisite that the knowledge upon which we start should be set right.

Whatever may be the future of the glycogenic theory, the substance which Bernard was the first to recognise will stand as it exists now. The name "glycogen" was applied to it when certainly an erroneous notion existed regarding the condition of the liver and of the blood in relation to sugar. Its presumed destination suggested the application of the term. I have hitherto objected to its employment, and I have stronger grounds for doing so now. To avoid the incorporation of theory, I have spoken, in my previous writings, of the body in question under the provisional name of "amyloid substance." Something more definite than this is for final purposes required, and it appears to me that it would be a fitting tribute to the memory of its discoverer to call it "Bernardin." Such a name will be at once suggestive of the substance to which it is intended to refer, and will form an imperishable memorial, which, whatever doctrine may prevail, will serve to identify the person, to whom all must admit physiological science owes so much, with the subject which formed the most prominent field of his labours.

Entering now upon the results which it is the object of this communication to make known, I will begin with the experiments bearing on the effect of bringing Bernardin (glycogen) into contact with blood. In these experiments the Bernardin was dissolved in a small quantity of water, and mixed with the blood in a defibrinated state. Sheep's blood was the kind of blood used. The product was placed in an oven specially constructed for such a purpose, and maintained for half an hour at a temperature between $100^{\circ}$ and $110^{\circ} \mathrm{F}$. It was then subjected to examination, and the quantity of sugar present ascertained by the ammoniated cupric test. ${ }^{2}$

In some instances the process of preparation for titration with the test consisted of extraction with alcohol, and in others of precipitation of the albuminous and colouring matters by heat with the aid of sulphate of soda. Bernardin (glycogen) prepared in different ways was used, and no difference in the results was perceived. Some of the specimens employed were obtained by simple extraction from the liver with water and precipitation with spirit. The actual condition of the specimen used as regards purity was ascertained by subjection to the converting action of sulphuric acid and heat, and the estimation of the glucose formed. In this way the information was obtained for supplying the figures found in the subjoined table representing the Bernardin used, expressed in its equivalent of glucose. The figures representing the sugar produced were obtained by deducting from the sugar found in the product of experiment the figures yielded by a specimen of the blood alone purposely exposed to parallel conditions.

2 The ammoniated cupric test referred to was described by me in communications to the Royal Society, published in vol. xxviii., p. 260 , and vol. xxix., p. $2 r_{2}$, of the Proceedings. Since bringing it under the notice of the Society, I have had a very large experience with it, and am thus enabled to speak in definite and confident terms about it. Its facility of application, delicacy, and precision place us in a most advantageous position in relation to the quantitative determination of sugar An important feature also belonging to it is that its action is not interfered with by the presence of nitrogenous matter, as is the case with the rdinary cupric solution. Under my supervision it has been used quite within bounds in aying some thousands of times; and if an quite within bounds in saying, some thousands of times; and if an ex perience of this kind will justify an expression of opinion, I may state that $I$ am satisfied it will be found invaluable alike to the phy siologist, the chemist, and the physician. The test is prepared by adding ammonia Cupric sulphate ......................... 34.65 grms.

Potassic sodic tartrate (Rochelle sait)................ 17

Water

For the ammoniated test 120 cub. centims. of the above solution are mixed with 300 centims. of strong ammonia (sp. gr. 0.880), and water added to a litre $20 \mathrm{cub}$. centims. of this ammoniated cupric liquid are decolorised by $0.010 \mathrm{grm}$. of glucose. The liquid to be examined is allowed to drop from a burette into a suspended flask containing the test, which is kept briskly boiling till decoloration has been attained. The reduction being attended with decoloration without precipitation there is nothing to obscure the determination of the moment when the precise point wanted has been reached. 
Bernardin (Glycogen) added to Blood and exposed for half an hour to a temperature of $100^{\circ}$ to $110^{\circ} \mathrm{F}$.

\begin{tabular}{|c|c|c|c|}
\hline & $\begin{array}{c}\text { Amount of Blood } \\
\text { used. }\end{array}$ & $\begin{array}{l}\text { Amount of Sugar } \\
\text { producible from } \\
\text { the Bernardin } \\
\text { mixed with the } \\
\text { Blood. }\end{array}$ & $\begin{array}{c}\text { Sugar } \\
\text { produced. }\end{array}$ \\
\hline 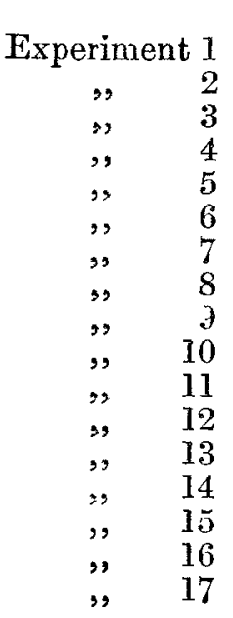 & $\begin{array}{c}\text { Cub. Centims. } \\
60 \\
60 \\
30 \\
30 \\
25 \\
50 \\
50 \\
50 \\
50 \\
50 \\
50 \\
50 \\
25 \\
50 \\
25 \\
25 \\
25\end{array}$ & $\begin{array}{l}\text { Grm. } \\
0.267 \\
0 \cdot 267 \\
0.535 \\
0.535 \\
0.232 \\
0.432 \\
0 \cdot 288 \\
0 \cdot 144 \\
0 \cdot 294 \\
0 \cdot 147 \\
0 \cdot 144 \\
0 \cdot 144 \\
0.144 \\
0 \cdot 144 \\
0 \cdot 144 \\
0.112 \\
0.112\end{array}$ & 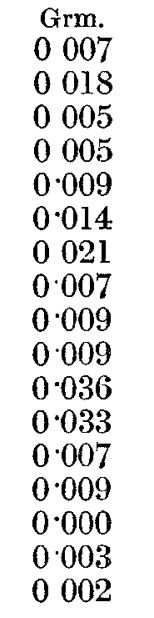 \\
\hline
\end{tabular}

The total of these results is that Bernardin (glycogen), equivalent to 4.085 grms. of glucose, was added to $705 \mathrm{cub}$. centims. of blood, and that the amount of sugar produced was 0.194 grm. I do not know the reason of the figures standing so much higher in Experiments 11 and 12 than in any of the others. The two were conducted together and with the same specimen of blood, which was only used for these experiments.

The a mount of sugar produced is too insignificant to be susceptible of recognition by ordinary testing. Half a gramme of a sample of Bernardin (glycogen), standing equivalent to $0.367 \mathrm{grm}$. of glucose, was mixed with 25 cub. centims. of blood, and exposed for half an hour to $100^{\circ} \mathrm{F}$. Prepared for testing with heat and sodic sulphate in the ordinary way, the product gave with the cupro-potassic test no visible indication of the production of sugar.

The point shown by these experiments is that Bernardin (glycogen) may be brought into contact with blood and kept in contact for some time at a temperature equal to that of the living body without undergoing conversion to more than what may be spoken of as quite an insignificant extent into sugar. Not only do the quantitative determinations of sugar prove this, but there is the further conclusive fact that the Bernardin is subsequently recoverable from the blood. The ground is therefore cleared in such a manner as to show that there is nothing inconsistent with Bernardin existing in and constituting a natural element of the blood.

Having established this foundation, I will now proceed to deal with the blood as it exists in the body, investigated in relation to Bernardin.

It is only when light begins to dawn upon a subject that the path of investigation, which is calculated tolead to an extension of knowledge, appears in view. Until a definite purpose to work up to, suggested by something or other which has been extricated from the domain of darkness is attained, engagement in the laboratory operations of research is unsatisfactory employment. For some time I persevered in conducting ceneral analytical examinations of the blood and liver, hoping that through the results obtained light might appear in some direction or other, but they failed to lead to any useful acquirement of knowledge. Later on, from information supplied by a collateral source of inquiry, I was induced to conduct examinations by another method of procedure, which was not likely to have been hit upon accidentally, and through these a new field has been opened out, which, if I judge rightly, has given signs of proving productive of an importint addition to our knowledge.

It would scarcely occur to a person, unless forced upon him by what he had otberwise observed, to think it necessary in relation to the matter under consideration to preserve the coagulated residue of blood and submit it to examination. It will be seen, however, from what has to be stated, that besides a certain amount of glucose which may be removed by alcohol, blood contains a principle which agrees with Bernardin (glycogen) in being insoluble in alcohol, and convertible into glucose by exposure to the influence of sulphuric acid and heat. Some of this principle is dissolved out by water under aqueous extraction, but the remainder clings to the coagulated residue, which has to be subjected to special treatment in order that it may be brought into view. Thus, unless a special mode of examination is adopted, which is not likely to suggest itself accidentally to the mind, the principle in question incorporated with the coagulated residue will remain concealed from observation.

In conducting a full or detailed examination of blood the first step to be undertaken is the separation of the glucose which it contains for quantitative examination. Let 25 to 50 cub. centims. of defibrinated blood be poured into five or six times their volume of spirit. The glucose being. soluble in alcohol is susceptible of extraction by this liquid. It is held, however, more tenaciously by the coagulated matter than might be expected, and hence to effect a complete removal several washings and pressings are required. At first I was deceived through not fully realising this circumstance, and thought I had obtained evidence of the presence of glucose, of a maltose-like body giving a greater cupric oxide reducing action after being subjected to the converting influence of sulphuric acid and heat than before, and of a substance agreeing with Bernardin (glycogen) in blood. The first $I$ found in the alcoholic extract, the second in the aquenus extract, and the third in the solid residue. The maltose-like body, I have since ascertained, has no real existence. The cupric oxide reducing action in the aqueous extract noticeable before subjection to sulphuric acid and heat, arose from the glucose not having been thoroughly extracted in the alcoholic process, and the increased reducing action after sulphuric acid and heat was due to the presence, in addition to the glucose referred to, of a little Bernardir (glycogen) dissolved out from the residue by the water.

The plan that I adopt for effecting the complete removal of the glucose is as follows: The defibrinated blood which has been taken for examination is poured into the requisite quantity of spirit, and the two are well stirred together. I am under the impression that it is advantageous for the coagulum to be allowed to remain in contact with the spirit till the following day. After heing boiled by the heat of the water bath, the alcohol is strained off through a piece of linen material which has been cleansed so as to be free from dressing. Washing with alcohol is performed, and the coagulum in the linen used is subjected to forcible squeezing in a suitable sized press. The residue, which by this process is converted into a dry cake, is pulverised in a mortar, mixed with fresh spirit, boiled over the water-bath, and again strailed and pressed. The process is repeated once more, and this I find is sufficient. Thus extracted three. times there is practically no glucose left in the solid residue, and when an aqueous extract is made it gives no appreciable cupric oxide reducing action before subjection to the influence of sulphuric acid and heat.

Two extractions with alcohol might prove sufficient if carefully made, but it is safer to use three. To give the representations of actual results yielded, $50 \mathrm{cub}$. centims. of sheep's blood were extracted with alcohol. The first: alcoholic extract contained $15 \mathrm{mgrms}$. of glucose, the second 4, and the third no definite amount. Some sugar from diabetic urine was added to sheep's blood, and $50 \mathrm{cub}$. centims. taken. The first alcoholic extract was found to contain 144 mgrms. of glucose, the second 9 , and the third nothing definite.

To prepare the alcoholic extraction for testing, the mixture of alcoholic liquids obtained is acidified with acetic acid, heated to nearly boiling-point over the water-bath, and then filtered through ordinary filtering-paper. It is now brought down by heat to a small bulk, and treated with an excess of crystals of sulphate of soda, with the view of causing the fatty matter finely dispersed through the liquid to agglomerate so as to be susceptible of removal by filtration. Water is added to the surplus crystals of sulphate of soda, and a hot solution made which is used for washing purposes.

The titration of the product of alcoholic extraction with the ammoniated cupric test gives quantitative results which stand in complete accord with those I obtained by the gravimetric process, which were mentioned in communications published in vol. xxvi., pp. 314 and 346, of the Proceedings of the Royal Society.

For the purpose of ascertaining what kind of sugar is contained in the alcoholic extract, the product of extraction has 
been titrated with the ammoniated cupric test before and after subjection to the converting influence of sulphuric acid and heat. The results have shown that no increased reducing action is given after treatment with sulpuric acid and heat.

The cupric oxide reducing principle, therefore, which is extracted by alcohol from blood, consists of glucose.

(To be concluded.)

\section{ON THE INFLUENCE OF CONSTITUTIONAL DRAINS UPON THE DEVELOPMENT OF CANCER.}

BY REGINALD HARRISON, F.R.C.S., SURGEON TO THE LIVERPOOL ROYAL INEIRMARY.

Is an address I recently delivered at the Liverpool Medical Institution, I urged the necessity for a still further search into the natural history of cancer as a likely means of adding to the limited resources we at present possess of controlling if not preventing it. There is one aspect of such an inquiry which it appears to me has not hitherto been sufficiently worked out, and that is the influence of what I may call constitutional drains, purulent or otherwise, on its production and reproduction. And though what I may have thought I observed, clinically, regarding this point in its bearing upon malignant disease may be of the nature of coincidences rather than of rules from which deductions are to be drawn, yet the narration of them may elicit from others similar or opposite conclusions, which still will be of value in making our knowledge of the life history of this disease more ample.

The frequent appearance of cancer in women at a time of life coincident with the withdrawal of a discharge has a significance when coupled with somewhat analogous circum. stances. Of the considerable number of cases of cancer that have fallen to my lot to see in a town where the opportunities for doing so are ample, I can recall to mind several where, after removal of the local disease had been effected, some independent discharge, such as a sinus or a fistula, accidentally followed, which so long as they existed seemed, as far as I was able to trace the cases, to ward off a recurrence of the malignant disease.

Though the patient in the following case has remained free from a return of the disease for only the comparatively short period of twenty-one months, yet it was just one where there was every reason to believe, from the extent to which the skin was implicated by scirrhous deposits, in ad. dition to other circumstances, that recurrence would probably be rapid. One case is that of Elizabeth $\mathrm{O}-$, aged forty, who was referred to me by Dr. Davidson, and whose breast I removed at the Infirmary on April 8th, 1879. It was necessary to sacrifice a large portion of the skin, so much so that the wound has never completely closed. Beyond this small wound, about the size of an ordinary issue, she has suffered no inconvenience whatever, and there is no appearance, either in the operation wound or elsewhere, of a return of the disease. She has gained flesh in spite of the slight purulent running I have mentioned, and looks robust and well. I have requested her to report herself from time to time, and not to allow the issue to heal. Though the time since the operation is far too short in this case to draw such a conclusion as I could wish, yet if recurrence were to take place almost immediately, I should still maintain, having regard to the nature of the primary disease that was removed, that recurrence had been considerably retarded by the protracted suppuration of a healthy sore. This case happened also to afford me the opportunity of referring to this subject in the course of my clinical teaching.

On October $7 \mathrm{th}, 1879$, I removed the breast of Mrs. W

a stout lady, for scirrhus, with the assistance of Mr. Byerley and Dr. Craigmile of Seacombe. She also was of such a habit of body that I should not have been surprised to hear that recurrence had taken place within rather less than the average time. In the following month she consulted me for a fistula in ano, which had suddenly appeared, and which I declined to interfere with. Writing to me on Jan. 29th, 1881, nearly sixteen months after the operation, Dr. Craigmile states, "She keeps very well and quite free from anything like a return either in breast or glands. The fistula now and then discharges very little, but gives almost no inconvenience."

Speaking generally, I have observed that when the removal of a cancer has been followed by a prolonged suppura. tion of the operation wound and its tardy closure, recurrence has been longer delayed than when union has been rapidly effected.

I remember a case occurring in 1860 , where, under the late Mr. Long's direction, I removed a scirrhus of the breast by chloride of zinc, which he was then trying in the infirmary. The action of the caustic was so potent as to damage the surface of one of the ribs, and for some years this patient lived with a persistent sinus which at times discharged minute portions of dead bone. With this ex: ception, for seven years I know she was in excellent healtb, and had no recurrence of the disease. About this time she left for America, and I have lost sight of her.

We must all have seen cases of malignant disease which have first shown themselves, in apparently middle-aged healthy persons without any known constitutional taint, a very short time after the sudden arrest of some long continuing drain, such as that of a fistula, or of bleeding hæmorrhoids. I can recall several. Again, the first appearance of cancer has been frequently observed in persons such as those I have mentioned, immediately after they have exchanged a life of bodily and mental activity for one of comparative indolence and luxury. Some of the most rapid and uncontrollable cases of cancer I have seen under these circumstances. For the most part cancer seems the more frequently to appear in the plethoric and torpid rather than in the spare. That a change of type in the individual who may be suffering from malignant disease is not unfrequently attended with some alteration in the growth has often been noted, and has served to explain instances where a cancer has ceased to show any signs of active progress. I believe that it would not be difficult to show that cancer is on the increase; that it is far more common amongst us now than it was one hundred years ago. If such a statement is correct, what bearing has it upon the advance of civilisation, of which we are disposed to boast?

It has often occurred to me whether our forefathers, who were shrewd observers, if they were not advanced pathologists, in the practising of the regular bloodlettings were quite as unreasonable in their views as to the "humours of the body" as we at the present day are disposed to regard them. Mas the use of drains and of setons, after the removal of the obvious signs of cancer, had a sufficient trial? I am disposed to think that it has not, and, further, that there exist grounds for their employment under certain conditions. I am now making use of them ; as, however, it is desirable to obtain as much collateral information upon this point as possible, to avoid the employment of treatment which has previously failed to give any encouraging results, I have taken the opportunity, when the attention of the profession has been more than usually directed to this subject, to refer to it in these columns. Of the various plans of treatment that have been adopted with the view of preventiog the recurrence of cancer, that of setons and issues will, I think, be found to afford the most promising results. Writing upon this subject, the late Mr. C. H. Moore remarks (Holmes's System of Surgery, vol, i., p. 605) "a greater good may be asserted to have attended the establishment of a slight drain from some part of the surface which is near enough to influence the locality of the disease, without itself being liable to taint [the italics are my own]. The existing evidence appears sufficient to warrant the insertion of a seton beneath the shoulder, after the patient has recovered from the effects of the operation of removing a scirrbous mamma."

Whether this deduction is drawn from the experience of the French surgeons Rayer and Boyer I cannot say; but if it were, and having regard to the very imperfect manner in which the primary disease was often removed before the general introduction of anæsthetics into surgical practice, $I$ should not be disposed to think that it represented the full amount of benefit which might accrue under the most favourable circumstances-that is to say, where a complete removal of all tissue obviously infected with cancer had been accomplished. One condition necessary to the obtaining of even such a partial success as the postponing of recurrence implies is obviously dependent upon the fulfilment of this. I cannot help agreeing with those who think that the 